\title{
Organic dust toxicity (pulmonary mycotoxicosis) associated with silo unloading
}

\author{
JOHN J MAY, LORANN STALLONES, DIANE DARROW, DAVID S PRATT \\ From the Sections of Pulmonary Medicine and Epidemiology, Department of Medicine, Mary Imogene Bassett \\ Hospital, Cooperstown, and the Department of Medicine, Columbia University College of Physicians and \\ Surgeons, New York, USA
}

ABSTRACT An acute febrile illness associated with unloading silos occurs more frequently than any other farm associated respiratory illness in mid state New York. This report describes 29 cases of organic dust toxic syndrome (also known as pulmonary mycotoxicosis) occurring in 24 men and one woman with a mean age of 29 years. In 16 instances more than one worker was exposed to the dust, and in 12 of these shared exposures more than one worker became ill. Patients presented 5.3 (SD $3.3)$ hours after inhalation of organic dust and mould with fever (79\%), myalgia (76\%), chest tightness $(72 \%)$, cough $(66 \%)$, and headache $(59 \%)$. The mean temperature was $38.7^{\circ} \mathrm{C}$ and the mean white blood cell count $13.2 \times 10^{9} / 1$. In contrast to patients with allergic alveolitis, nearly all these patients had normal breath sounds, chest radiographs, and arterial oxygen saturation. Tests for precipitating antibodies to farmer's lung disease antigens gave negative results in all 26 episodes in which they were done; of these, 10 had no evidence of precipitating antibodies to an aqueous extract of the silage associated with their own illness. Organic dust toxic syndrome appears to be a common and substantial respiratory hazard to young farm workers. Despite being frequently misdiagnosed as farmer's lung, organic dust toxic syndrome is clearly a distinctly different disease process.

In 1975 Emanuel et al reported an acute, febrile illness occurring in 10 workers after "massive fungal inhalation in their silos." Although this disorder had been described a year previously in a single patient as "precipitin test negative farmer's lung,"2 Emanuel's group elected to call it "pulmonary mycotoxicosis." In doing so they endorsed the earlier suppositions of Samsonov and other Russian observers that such illnesses might represent a systemic reaction to inhaled fungal toxins. ${ }^{3}$

In the 10 years since these reports appeared, "pulmonary mycotoxicosis" has remained little more than an obscure medical curiosity. There have been no additions to the 11 cases described in the mid 1970s. Animal studies have further documented the inflammatory potential of inhaled silage dust, ${ }^{4}$ but no evidence has been presented to support an aetiological role for fungal toxins.

We have recently reported the results of a survey of patients admitted to hospital for occupational respi-

Address for reprint requests: Dr John May, Department of Medicine, Mary Imogene Bassett Hospital, Cooperstown, New York 13326, USA.

Accepted 30 June 1986 ratory illness in central New York dairy farmers. ${ }^{5}$ In this survey we identified 20 individuals with a disease that appeared to be farmer's lung disease. Further investigation of the specific details of each episode, however, revealed two distinct patterns. Six of the individuals clearly had farmer's lung, but the remaining 14 did not. Instead of showing the typical radiographic, blood gas, and pulmonary function findings of farmer's lung, these patients had a clinical presentation that was subtly but perceptibly different. Subsequent precipitin testing seemed to confirm our doubts about farmer's lung. These 14 patients had experienced the illness previously described by Emanuel et al. Because virtually all of our cases (like those of Edwards and Emanuel) occurred after the opening of a silo, we chose to refer to this illness as "silo unloader's syndrome." Subsequently, an international workshop on agricultural organic dusts has recommended that this disorder be referred to as the "organic dust toxic syndrome."6

Education of farmers and others has led to increased recognition of the disorder. In the present report we describe in detail 29 episodes of organic dust toxic syndrome occurring in the central New York State region. 


\section{Patients and methods}

The 29 episodes occurred in 25 individuals. Fifteen of these were interviewed and examined by one of the investigators, 13 during the acute episode and two after the episode. A complete history was taken and a physical examination performed in each case. Blood counts, arterial blood gas analysis, chest radiography, pulmonary function tests and serum antibody testing were undertaken whenever possible. The remaining 10 patients were not seen by the investigators in the acute illness but were discovered by review of case notes from our institution and from other hospitals in our region after initial contact had been made by the farmer, a family member, or a physician. In each instance all records were reviewed and each individual was interviewed retrospectively. Whenever possible, serum samples were obtained from the time of the hospital admission. Cases were excluded if details of the exposure, symptoms, findings on chest examination, and chest radiograph were not available.

Each exposure was reviewed. Information was gathered about the time interval from exposure to onset of illness, symptoms experienced by coworkers, the patient's location in the work area, the length of exposure, the type of structure concerned, and the type of feed grain. Detailed information was obtained about the harvesting, storing, and handling of the feed.

Pulmonary function testing was performed with a Collins Maxi-System (W E Collins, Braintree, Massachusetts) in 11 cases. Total lung capacity was determined by the helium dilution technique. Transfer factor for carbon monoxide was measured by the single breath technique.

Antibody testing against various farmer's lung antigens was done by immunodiffusion at one of two large reference laboratories $(80 \%$ at the Mayo Medical Laboratory, Rochester, Minnesota, and the rest at the New York State Laboratory, Albany). Antibodies to Micropolyspora faeni, Thermoactinomyces vulgaris, $T$ viridis, Aspergillus fumigatus, A niger, and Alternaria spp were sought. In 10 cases samples of silage associated with the illness as well as serum were stored at $-70^{\circ} \mathrm{C}$. From four of these individuals ano additional late serum sample was obtained six or more weeks after the illness.

Serum was concentrated fourfold by suction dialy- $\frac{\widehat{\Phi}}{\circ}$ sis in veronal buffer. Immunodiffusion testing was then performed by the micro-Ouchterlony technique ${ }_{-}$ with the concentrated serum in the centre well and? serial 1:2 dilutions of the appropriate silage extract $\vec{\omega}$ around the periphery. This extract was the super-o natant from a suspension of 1 gram of silage incu- $\vec{x}$ bated in $10 \mathrm{ml}$ of veronal buffer. ${ }^{7}$ Paired serum and silage samples from three individuals with known farmer's lung served as positive controls.

Patients were considered to have organic dust toxic $\frac{6}{6}$ syndrome if they showed typical clinical signs of ill-o ness occurring up to 12 hours after a massive inhalation exposure to organic material and dust. Physically demanding labour without respiratory专 protection in an atmosphere that was visibly heavily contaminated with organic dust for more than 30 엉 minutes was held to be consistent with a massive inhalation exposure. Cases where evidence suggested $\vec{\oplus}$ a diagnosis of farmer's lung were excluded (that is, positive reactions in precipitin tests in the presence of clinically significant alveolitis (arterial desaturation, abnormal chest radiograph, restrictive alteration of pulmonary function)).

\section{Results}

This series includes 29 cases of organic dust toxic syn- $\frac{3}{3}$ drome occurring in 25 individuals after 23 separate work exposures. Four of the workers had two separate episodes. The affected farmers included 24 men $\vec{\circ}$ and one woman with a mean age of 29.9 (SD 14.2) years. On the day of their illness farmers had spent an average of $3.4(2.8)$ hours working in a dusty environment.

In 16 of the 23 exposure episodes more than one person was working in the silo. In 12 of these sharedo exposures at least one other worker was found to have experienced symptoms of organic dust toxic syn-o drome. Nineteen $(82 \%)$ of the exposures occurred in silos and two $(9 \%)$ in corn cribs. Autumn was the

Table 1 Clinical presentation

\begin{tabular}{|c|c|c|c|}
\hline Signs and symptoms & $(\%)$ & Laboratory findings & $(\%)$ \\
\hline $\begin{array}{l}\text { Temperature }>38^{\circ} \mathrm{C} \\
\text { Myalgia } \\
\text { Chest tightness } \\
\text { Cough } \\
\text { Headache } \\
\text { Malaise } \\
\text { Dyspnoea } \\
\text { Crackles }\end{array}$ & $\begin{array}{l}23 / 29(79) \\
22 / 29(76) \\
21 / 29(72) \\
19 / 29(66) \\
17 / 29(59) \\
17 / 28(60) \\
16 / 28(57) \\
4 / 29(14)\end{array}$ & $\begin{array}{l}\text { Normal chest radiograph } \\
\text { Antibody negative } \\
\text { Arterial oxygen tension }>70 \mathrm{~mm} \mathrm{Hg} \\
\text { Leucocyte count }>10 \times 10^{9} / 1 \\
\text { Forced vital capacity } \\
\text { Functional residual capacity } \\
\text { Single breath diffusion (transfer factor) }\end{array}$ & $\begin{array}{l}29 / 29(100) \\
26 / 26(100) \\
17 / 19(90) \\
17 / 18(94) \\
10^{*} / 11(91) \\
7 * / 11(64) \\
10^{*} / 11(91)\end{array}$ \\
\hline
\end{tabular}


peak period for incidents; $15(66 \%)$ of the episodes occurred in September and October, and virtually all episodes ( 21 or $93 \%$ ) occurred from July to October. Chopped hay silage featured in $16(70 \%)$ of illness related exposures and corn silage accounted for a further six exposures $(26 \%)$.

\section{CLINICAL PRESENTATION}

In the 28 episodes where the information was available, the onset of symptoms was noted by our farmers $5 \cdot 3$ (SD 3.3) hours after their exposure. The most common symptoms noted in the 29 episodes were: temperature over $38.0^{\circ}$, myalgia, chest tightness, cough, and headache (table 1). At least four of these symptoms occurred in 15 cases and at least three in 22 cases. Symptoms occurring less commonly included nausea, vomiting, and shaking chills.

These patients generally appeared febrile and unwell when examined during the acute phase of the illness. Most had tachypnoea and tachycardia, with a mean temperature of $39.0^{\circ}$ (SD $0.6^{\circ}$ ) in those who were febrile. Auscultation of the chest indicated the presence of crackles in four (14\%). Findings on physical examination were otherwise unremarkable.

\section{LABORATORY EVALUATION}

In the 18 cases with white blood cell counts available the mean (SD) white cell count was $13.2(3.0) \times 10^{9} / 1$. Leucocytosis as high as $17.6 \times 10^{9} / 1$ was noted in one instance. There was a striking predominance of neutrophils $(84 \%(6 \%))$ and band forms with virtually no eosinophils (mean $\left.0.2(0.6 \%) \times 10^{9} / 1\right)$. Arterial blood gas tensions (17 cases) showed widening of the alveolar-arterial oxygen gradient $\left(\mathrm{A}-\mathrm{aDo}_{2}\right)$ to 25.7 $(13.8) \mathrm{mm} \mathrm{Hg}(3.3(1.8) \mathrm{kPa})$ despite a relatively normal mean room air arterial oxygen tension $\left(\mathrm{PaO}_{2}\right)$ of $79 \cdot 2(15 \cdot 3) \mathrm{mm} \mathrm{Hg}(10 \cdot 3(2 \cdot 0) \mathrm{kPa})$. Appreciable arterial desaturation was noted in only one instance, where the saturation fell to $78 \%$. Chest radiographs were available for each episode and all were normal. Precipitating antibodies to standard farmer's lung antigens were absent in all 26 cases in which the tests were done. Immunodiffusion testing using paired serum-silage samples was performed in 10 patients. In four of these, late serum samples were also tested. In no instance were precipitating antibodies to the paired silage extract detected.

Pulmonary function testing was carried out in 11 individuals during the acute illness. They had a mean forced vital capacity (FVC) of $91.7 \%(9.6 \%)$ of their predicted normal values. Total lung capacity (TLC) was $84.4 \%(11.5 \%)$ of predicted, and transfer factor (TLCO) was $104.2 \%(17.0 \%)$ of predicted. One individual was tested during the first eight hours of symptoms. His FVC was $96 \%$, TLC $100 \%$, and TLCO $121 \%$.

\section{OUTCOME}

Thirteen of $29(45 \%)$ occurrences resulted in admission to hospital, with an average stay of 3.8 (SD 2.2) days. Twenty one farmers reported a total of 108 lost work days, or $3.7(3.4)$ days per case, with $72 \%$ of those missing work losing 1-4 days. A physician other than one of the investigators made a diagnosis in 20 of the cases. Most diagnoses were of "farmer's lung disease" $(65 \%)$, with "silo filler's disease" $(30 \%)$ and "viral pneumonitis" (5\%) accounting for the remainder.

\section{Discussion}

Since milk production and profit depend on high quality yet economical feed, most dairy farmers rely upon feed stored in silos and supplemented with added nutrients. After cutting, grasses (haylage) or corn (corn silage) are wilted briefly in the field, then chopped and blown into the silos for storage. The environment of the packed silage promptly becomes anaerobic and thereafter concentrations of lactic and other organic acids rise steadily. The attendant fall in $\mathrm{pH}$ eventually inhibits all microbial growth, thus limiting spoilage. The uppermost layers, however, remain aerobic and are rapidly overgrown with various bacteria and fungi. Thermophiles especially appear to thrive in the warm silo environment. After an interval of weeks or months the stored silage is fed to cattle, a mechanical device being used to unload the silo. To initiate unloading, however, farm personnel must remove by hand the contaminated top silage layer or "cap," which generally extends down 2-4 ft $(0 \cdot 6-1.2 \mathrm{~m})$ and may amount to several tons of material. The job may take several hours, during which this material has to be thrown some 50-60 ft (about 15-18 $\mathrm{m}$ ) down a chute $3 \mathrm{ft}$ (about $1 \mathrm{~m}$ ) in diameter. A chimney effect tends to aerosolise the dust, organisms, and spores, circulating them back up to the top of the silo. Once the top layer is pitched down, this material must be loaded into a wagon and removed from the area. Thus the work environment may become extremely dusty both in the silo room at the bottom of the chute and inside the silo itself. Farmers have described being unable to see more than 1 or $2 \mathrm{ft}$ in any direction during this uncapping process.

The lung serves as the major site of exposure to this dusty organic material. In the sole report of a lung biopsy after such an exposure inflammation was described at the level of the terminal bronchioles and alveoli. ${ }^{1}$ Despite the probable inflammatory response caused by this dust, the behaviour of the lung in our patients was not substantially altered either mechanically or functionally. Although our patients rarely had entirely normal oxygenation (mean A-aDo 25.7 $\mathrm{mm} \mathrm{Hg}-3.3 \mathrm{kPa}$ ), substantial haemoglobin 
Table 2 Contrasts between farmer's lung disease (FLD) and organic dust toxic syndrome (ODTS)

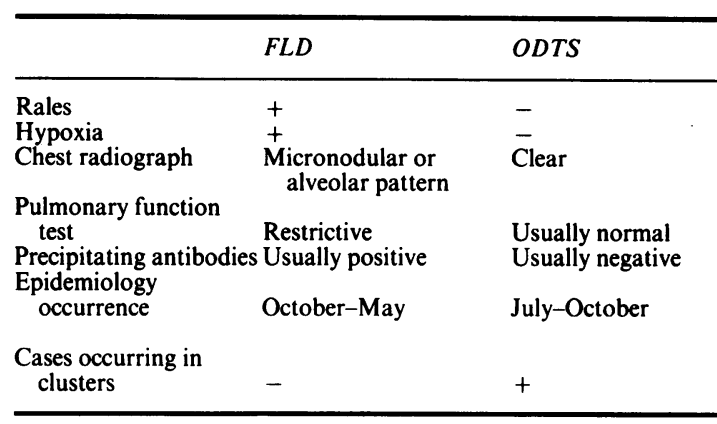

desaturation was distinctly unusual (only one out of 17 tested had a haemoglobin oxygen saturation below $90 \%$ ). Pulmonary function tests in the acute episode showed boderline reduction of total lung capacity with preservation of single breath diffusing capacity (transfer factor). On no occasion did the chest radiograph show signs of interstitial or alveolar inflammation.

Although acute farmer's lung also causes fever, cough, malaise, and myalgia after a lag period of several hours, we consider that there is ample evidence, both clinical and epidemiological, that organic dust toxic syndrome is not simply a variant of farmer's lung (table 2). Clinically, the absence of crackles, radiographic abnormalities, and clinically significant arterial desaturation all argue strongly that this is not acute farmer's lung. Additional evidence is offered by the absence of precipitating antibodies. It might be argued that such antibodies could have been missed in the instances where the serum was tested against a panel of farmer's lung antigens in a reference laboratory. No such objection can be raised in the 10 cases where serum samples were tested against the silage itself. Farmer's lung may rarely occur in the absence of precipitating antibodies, but the consistent absence of antibodies to the known causative agent gives added support to our contention that organic dust toxic syndrome is a different phenomenon from farmer's lung. Although micro-Ouchterlony testing is less sensitive than some other methods of antibody detection, this technique has been shown to be superior to counterimmunoelectrophoresis and is one of the recommended methods for routine detection of antibody in hypersensitivity lung disease. ${ }^{10}$ The sensitivity of the assay for antibodies against silage extract is enhanced by the prior concentration of the serum and has been sufficient to detect antibody consistently in those with known farmer's lung.

Review of the epidemiology of the two disorders provides even further proof of the distinction. The peak season for farmer's lung is generally acknowledged to be between late autumn and spring. ${ }^{11} 12$ Yet $\frac{\bar{O}}{\bar{\omega}}$ $93 \%$ of these episodes of organic dust toxic syndrome occurred from July to October, no cases being noted $\propto$ from December to June. Finally and most is significantly, our findings demonstrate that when this $\overrightarrow{0}$ syndrome occurs it tends to affect most of the workers $\overrightarrow{-}$ exposed. Of 16 episodes affecting more than one $\vec{\omega}$ worker, the coworker or coworkers experienced at least some symptoms in $12(75 \%)$. Edwards ${ }^{2}$ and $\times$ Emanuel $^{1}$ also document this phenomenon. Farmer's $\triangleq$ lung, on the other hand, is estimated to affect $4 \%$ or $\vec{N}$ less of the farm population. ${ }^{13}$ Thus the likelihood of 6 two, three, or four individuals susceptible to farmer's $\overrightarrow{0}$ lung working together in a silo and thus producing a 음 cluster of cases of farmer's lung would seem, at best, $\rightarrow$ remote. The likelihood of seeing such an occurrence $75 \%$ of the time is virtually zero. Certainly medical $\varnothing_{\mathbb{D}}$ publications support the view that farmer's lung 3 affects family members or coworkers very rarely. ${ }^{11} 14 \stackrel{\mathbb{D}}{1}$

Despite strong evidence that organic dust toxic syn- $\vec{\circ}$ drome is a different phenomenon, it is probably fre- $\infty$ quently mistaken for farmer's lung. The tendency to mistake organic dust toxic syndrome for farmer's lung may well extend into previously published work. Since exposure to mouldy hay or corn may have been $\bar{\partial}$ as important a diagnostic criterion as having anti- $\bigcirc$ bodies to farmer's lung antigens or an appropriate $\varrho$ clinical presentation in certain studies, possibly some $\overrightarrow{\overrightarrow{0}}$ authors have included cases of organic dust toxic syn- 3 drome in their series of farmer's lung. Reports in which most farmers did not have abnormal chest radiographs and in which precipitin testing often gave negative results ${ }^{1214}$ might well contain such cases. $\frac{\text { 응 }}{2}$ Obviously, such an error might affect some of the $\times$ conclusions reached about incidence, severity, and $\frac{0}{3}$ prognosis in farmer's lung.

We do not consider that organic dust toxic syndrome is a disorder limited to the farm environment. Rather, we have been impressed by its striking simi- $\frac{\text { 일 }}{7}$ larity to other phenomena such as "mill fever" in cot- $\frac{7}{0}$ ton workers 15 and "grain fever" in storage elevator workers. ${ }^{16}$ The fact that in many of our cases organic $N$ dust toxic syndrome appeared substantially more $N$ severe than some of these other disorders may partly reflect a selection bias in our series but may also $\omega$ reflect the prodigious inhalation exposure that can occur with the opening of a silo. Lacey et al have $\stackrel{\circ}{C}$ documented levels of $1.6 \times 10^{9} \mathrm{spores} / \mathrm{m}^{3}$ in previous farm studies. ${ }^{17}$ Studies that we have recently com- pleted suggest that the spore concentrations associ- $\frac{0}{0}$ ated with the opening of some silos may substantially exceed those reported by Lacey. ${ }^{18}$

As with these other disorders, the pathogenesis of $\stackrel{\mathbb{Q}}{2}$ the illness in organic dust toxic syndrome is unknown.? The possibility of fungus derived toxins has been con- 8 
sidered and was favoured by Emanuel et al. ${ }^{1}$ Attempts to detect mycotoxins, however, in some of our silage samples associated with organic dust toxic syndrome by means of gas chromatography and mass spectroscopy have been unsuccessful. ${ }^{18}$ The possible role of complement in this reaction was suggested by Edwards's demonstration of alternative pathway activation by silage dust. ${ }^{2}$ Marx et $a l,{ }^{4}$ noting an increased proportion of bacteria in silage dust associated with disease, proposed that the complement activation might be related to endotoxin. Interestingly, Rylander has advanced strong arguments favouring a causative role for endotoxin in the "mill fever" experienced by cotton workers. ${ }^{19}$

Although organic dust toxic syndrome seems clinically distinct from farmer's lung the similarities between organic dust toxic syndrome and some forms of extrinsic allergic alveolitis cannot be completely ignored. Positive challenge tests in bird fancier's disease $^{20}$ may result in a picture identical to organic dust toxic syndrome, albeit at exposure levels that are seemingly much less intense than those experienced by our farmers. Apparently when these inhalation provocation tests use more intense ("unnecessarily severe") exposures signs of the typical farmer's lung type alveolitis (rales, reduced carbon monoxide transfer, and radiographic changes) may occur. ${ }^{20}$ These somewhat similar clinical patterns may arise from different basic mechanisms-an acute unidentified intoxication in organic dust toxic syndrome and an immune mediated response in farmer's lung. Alternatively, these could be manifestations of the same phenomenon, but occurring at widely divergent threshold levels. Clearly, considerable work remains to be done before we understand the mechanism of organic dust toxic syndrome and its precise relationship, if any, to extrinsic allergic alveolitis.

This research was supported in part by grants from the Agway Foundation and the Stephen C Clark Foundation. We appreciate the cooperation and support of Dr Curry Marr, Claude Rose, and the Bassett Hospital word processing staff.

\section{References}

1 Emanuel DA, Wenzel FJ, Lawton BR. Pulmonary mycotoxicosis. Chest 1975;67:293-7.

2 Edwards JH, Baker JT, Davies BH. Precipitin test negative farmer's lung - activation of the alternative pathway of complement by moldy hay dusts. Clin Allergy 1974;4:379-88.
3 Samsonov PF. In: Bilai VI, ed. Mycotoxicoses of man and agricultural animals. Kiev: Izd Akad Nauk Ukr SSR, 1960:131-51.

4 Marx JJ, Arden-Jones MP, Treuhaft MW, Gray RL, Motszko CS, Hahn FF. The pathogenic role of inhaled microbial material in pulmonary mycotoxicosis as demonstrated in an animal model. Chest 1981;81 (suppl):76-8S.

5 Pratt DS, May JJ. Feed-associated respiratory illness of farmers. Arch Environ Health 1984;39:43-8.

6 doPico GA. International Workshop on Health Effects of Organic Dusts in the Farm Environment, Skokloster, Sweden: 23-25 April 1985. Am J Indust Med 1986;10:261-5.

7 Olenchock SA, Christian DC, Mull JC, Ting-ting Y, PeiLian L. Endotoxins in baled cotton and air borne dust in textile mills in the People's Republic of China. Appl Environ Microbiol 1983;46:817-20.

8 Morris JF, Koski A, Johnson LC. Spirometric standards for healthy non-smoking adults. Am Rev Respir Dis 1971;103:57-67.

9 Gaensler EA, Wright GW. Evaluation of respiratory impairment. Arch Environ Health 1966;12:146-89.

10 Flaherty DK, Barboriak J, Emanuel D, et al. Multilaboratory comparison of three immunodiffusion methods used for the detection of precipitating antibodies in hypersensitivity pneumonitis. $J$ Lab Clin Med 1974;84:298-306.

11 Emanuel DA, Wenzel FJ, Bowerman CI, Lawton BR. Farmer's lung. Clinical, pathologic, and immunologic study of twenty-four patients. Am J Med 1964;37: 392-401.

12 Grant IWB, Blyth W, Wardrop VE, Gordon RM, Pearson JCG, Mair A. Prevalence of farmer's lung in Scotland: a pilot study. Br Med J 1972;i:530-4.

13 Madsen O, Klock LE, Wenzel FJ, Robbins JL, Schmidt CO. The prevalence of farmer's lung in an agricultural population. Am Rev Respir Dis 1976;113:171-4.

14 Hapke EJ, Seal ME, Thomas GO, Hayes M, Meck JC. Farmer's lung. A clinical, radiographic, functional, and serological correlation of acute and chronic stages. Thorax 1968;23:451-68.

15 Merchant JA, Halprin GM, Hudson AR, et al. Responses to cotton dust. Arch Environ Health 1975;30:222-9.

16 Kleinfeld M, Messite J, Swencichi RE, Shapiro J. A clinical and physiologic study of grain handlers. Arch Environ Health 1968;16:380-4.

17 Lacey J, Lacey ME. Spore concentrations in the air of farm buildings. Trans Br Mycol Soc 1964;47:547-52.

18 May JJ, Pratt DS, Stallones L, et al. A study of silo opening: the work environment and its physiologic effects [abstract]. Am J Ind Med 1986;10:318.

19 Rylander R. Bacterial toxins and the etiology of byssinosis. Chest 1981;79 (suppl):34-7S.

20 Hendrick DJ, Marshall R, Faux JA, Krall JM. Positive "alveolar" responses to antigen inhalation provocation tests: their validity and recognition. Thorax 1980;35:415-27. 